\title{
CORRECTION
}

View Article Online

View Journal | View Issue

W) Check for updates

Cite this: RSC Adv., 2021, 11, 34923

rsc.li/rsc-advances

\section{Correction: Synthesis and functional studies of self- adjuvanting multicomponent anti-HER2 cancer vaccines}

Qi Feng, ${ }^{\text {*abcd }}$ Xiaoyue Yu, ${ }^{\text {be }}$ Yixue Wang, ${ }^{\text {abcd }}$ Shiyang $L^{\text {abcd }}$ and Yang Yang ${ }^{\text {*f }}$

Correction for 'Synthesis and functional studies of self-adjuvanting multicomponent anti-HER2 cancer vaccines' by Qi Feng et al., RSC Adv., 2021, 11, 33814-33822, DOI: 10.1039/D1RA06146A.

The authors regret that the authors were affiliated with the incorrect institutions in the original manuscript. The corrected author list and affiliations are as shown above.

The Royal Society of Chemistry apologises for these errors and any consequent inconvenience to authors and readers. 